\title{
Um encontro com as fontes em História Oral
}

\author{
Marcos Fábio Freire Montysuma*
}

\begin{abstract}
Resumo: Neste trabalho refletimos sobre a produção e os usos das fontes e dos instrumentos metodológicos que orientam as ações na condução do trabalho do historiador que lida com o que se convencionou chamar História Oral. Buscamos discutir a singularidade do trabalho de campo, envolvendo a relação entre o pesquisador e as pessoas ouvidas, como condição de uma ciência que lida essencialmente com o indivíduo.
\end{abstract}

Abstract: In this article we reflect upon the production and uses of sources and methodological tools which guide the actions of the historian who deals with the field conventionally referred to as Oral History. We aim at discussing the singularity of field work, bringing into play the relationship between the researcher and people who are listened to - a vital condition for a science that essentially deals with the individual.

Palavras-chave: Fontes. Metodologia. História Oral.

Key words: Sources. Methodology. Oral History.

Os conteúdos que nos propomos a abordar nessa oportunidade, integram uma discussão em torno de metodologia e fontes em História Oral, que muito são buscados por quem está se iniciando no trato com essas questões, por isso nos dedicamos, neste momento, a refletir sobre a produção e os usos das fontes e dos instrumentos metodológicos que orientam as ações, na condução do trabalho do historiador, que lida com o que se convencionou chamar História Oral. Para tal, buscamos discutir a singularidade do trabalho de campo, envolvendo a relação entre o pesquisador e as pessoas que se dispõem a nos prestar um relato, como condição de uma ciência que lida essencialmente com o sujeito. Logo, estamos envolvidos com uma práxis que nos remete a questões situa-

Professor do Departamento de História-UFSC. E.mail: mmontysuma@aol.com.

Estudos Ibero-Americanos. PUCRS, v. XXXII, n. 1, p. 117-125, junho 2006 
das em posturas éticas, uma vez que lidamos com interpretações de relatos significados na memória, contidas nas falas das pessoas. A ação de pesquisar através do contato com seres humanos resulta na possibilidade de produção de materiais fabulosos, que exigem tratamentos e destinos apropriados, como uma condição para assegurar a seriedade e a continuidade do trabalho realizado em campo e por extensão, do nosso ofício.

Percebemos que muito temos falado de História Oral nos nossos espaços de trabalho. Apresentamos nossos textos e livros que tratam de História Oral. Porém, nossos alunos, quando se lançam à pesquisa, ficam carecendo de meios concretos de procedimentos e quais os destinos que devem dar aos materiais produzidos. Daí surgiu a idéia de preparar uma disciplina, que chamamos de História Oral - Instrumental e Teórica, buscando dar conta de algumas questões que julgamos importantes, para que mais pesquisadores sejam incorporados à calorosa confraria daqueles que trabalham com História Oral. Isso também decorreu do fato de ter trabalhado no ramo meio às cegas, aprendendo tateando, e da preocupação que temos, ao ver pessoas com bom potencial, enveredando por caminhos que entendemos questionáveis ou comprometedores para nosso ofício.

Buscando abranger as questões suscitadas no parágrafo anterior, para que possamos refletir um pouco mais sobre o nosso ofício, trazemos aqui algumas situações para que possamos agir sem tantas angústias.

Vejamos alguns aspectos que nos importunaram quando realizamos nossa primeira pesquisa envolvendo a História Oral. Naquela oportunidade, levamos bolsistas do Programa de Iniciação Científica - PIBIC ao trabalho de campo. Considerando o fato de ser originário da região e haver trabalhado como assessor do Sindicato dos Trabalhadores Rurais de Xapuri, entre 1983/84, na época em que Chico Mendes fora presidente, pensávamos que ao contatar uma pessoa, para que relatasse sua vida na floresta, teríamos de imediato alguém disponível a falar tranqüilamente, sem nenhum tipo de distanciamento, desconforto, ou desconfiança. Percebemos através do contato com as pessoas já conhecidas, desde os idos de 1980, a existência de uma recepção e um aceite de nossa presença, transparecendo posturas de confiabilidade em relação ao entrevistador. Porém, o contato com as pessoas que não nos conheciam resultaram em depoimentos que transcorriam noutro nível, que poderemos entender como de desconfiança em relação a nós. Com a experiência acumulada nos anos seguintes, percebemos que fal- 
tou em nós a devida atenção para nos fazer apresentar devidamente aos nossos entrevistados.

A conseqüência disso é que o trabalho realizado com mulheres e homens quando havia uma cumplicidade, as entrevistas foram bastante produtivas, ricas em muitos aspectos. Já não podemos falar o mesmo com relação àquelas entrevistas realizadas com as pessoas em que o ingrediente do "desconhecido" estava presente.

A História Oral não tem como condição de sua existência operar através dos relacionamentos de amizade. Um contato inicial sem referências e até distanciado, pode vir a converter-se numa amizade futura, dependendo muito da forma como os sujeitos se relacionam. Conforme nos foi apresentado por Alistair Thomson, ${ }^{1}$ que se envolveu numa relação dessa natureza com Bill e Fred Farrel, que foram seus entrevistados, falando sobre memórias de guerra.

O aprendizado que tiramos do episódio acontecido nessa viagem a Xapuri, que nos foi muito útil mais tarde, é que lidamos com a subjetividade humana, logo o modo como cada pessoa percebe o outro constitui ingrediente essencial, que finda por refletir nos resultados ou na qualidade do trabalho que realizamos. Não basta pertencer a uma mesma região, ou ter uma história comum aos sujeitos entrevistados para que nos aceitem, e passem a falar abertamente de suas vidas, de suas memórias, como se integrássemos seus grupos familiares, de amizades e fidelidades. Uma amizade prévia pode ajudar o entrevistado a falar sem pudores, por confiar no seu interlocutor; mas também pode atrapalhar, na medida que tudo que se perguntar "já se sabe diante mão a resposta". Nesse caso, a pergunta pode sair direcionada, ou no momento de elaborá-la o pesquisador já toma a palavra da pessoa se encaminhando na resposta, tangendo- $a$ para a condição de coadjuvante, através de afirmativas positivas, tais como: sim, verdade, foi, é, concordo, você tem razão. Sem possibilitar à pessoa a chance de exercitar a memória, elaborar suas interpretações e leituras referentes ao assunto, para manifestar-se livremente segundo suas concepções e conveniências. Achamos importante a postura adotada por Mercedes Vilanova, ${ }^{2}$ que nos cai como uma lição de mestre, e nos serve como referência, quando nos lançamos a campo, com nossos instrumentos de trabalho. Ao discutir sua experiência como pesquisadora, ela diz que se dispõe a falar de sua subjetividade, manten-

THOMSON, A. Debate. Projeto História, São Paulo, Educ, n. 15, 1997, p. 73.

VILANOVA, Mercedes. Pensar a subjetividade - estatísticas e fontes orais. In: MORAES, Marieta (Org.). História Oral. Rio de Janeiro: Diadorim, 1994, p. 46. 
do cuidado para não ser paternalista retirando a palavra dos outros.

É necessário perceber que em nosso ofício, para que possamos exercitá-lo com o êxito de obter uma gravação com os ingredientes essenciais ao trabalho posterior, convém que reconheçamos a existência de uma relação de poder entre os sujeitos, entre entrevistador e entrevistado, mas jamais a supressão da palavra, da voz do outro. Para o entendimento corrente de que o poder de julgar está circunscrito a quem detém os instrumentos de dominação numa sociedade; no caso da pesquisa esses instrumentos se expressam através da lapiseira ou do gravador, ${ }^{3}$ dado que quem os manipula é o entrevistador, porém ocorre a inversão desses papéis, visto que o poder também está do outro lado, na medida em que a pessoa que relata também julga e elabora conceitos. $\mathrm{O}$ de julgar o outro se direciona tanto ao seu interlocutor, o pesquisador, quanto aos fatos que narra. Escolher o que relatar já implica num juízo de valor circunscrito a quem detém o poder através da fala.

Alistair Thomson, ${ }^{4}$ nos remete ao entendimento de que o material essencial que constrói a cumplicidade, sedimentando a relação de confiança, entre entrevistador e entrevistado, é a sinceridade, que é uma condição do nosso ofício. A clareza com que falamos do nosso papel, quando nos apresentamos para as pessoas, lhes solicitando uma entrevista, estará presente até o encerramento do trabalho.

Mudando um pouco os ingredientes, gostaria de trazer para nossas reflexões o filme Kinsey - Vamos falar de sexo..$^{5}$ Quando o personagem Dr. Alfred Kinsey vai pesquisar a sexualidade masculina, nos Estados Unidos, na década de 1940, apresenta numa das seqüências como ocorre a preparação de sua equipe de entrevistadores, formada, no início, exclusivamente por homens, sob sua coordenação. Submete-os a um exaustivo e metódico laboratório, exercitando, internamente no grupo, a simulação do contato com pessoas entrevistadas. Nesses exercícios, são provocados a falar abertamente, com sinceridade sobre os assuntos a que se propõem.

3 PORTELLI, Alessandro. A filosofia e os fatos. Tempo, Rio de Janeiro, Relume Dumará, v. 1, n. 2, 1996, p. 62.

4 THOMSON, loc. cit., p. 73

5 KINSEY - vamos falar de sexo, Fox SearchughtPictures, Dir. Bil Condoml, Prod. Bill Condom, Liam Neeson e Laura Linney. Chris O'Donnell, Peter Sarsgaard, Timothy Hutton, John Lithgow, Tim Curry, Oliver Platt, Dylan Baker, EUA, 2005, 2.31:1, color. 
O que nos interessa discutir no campo da História Oral são os elementos apresentados no filme em relação ao treinamento da $a$ presentação do entrevistador perante as pessoas, como um comportamento que envolve o pesquisador na obrigação de se relacionar com sinceridade, quando apresenta questionamentos. Uma sinceridade não impositiva, não autoritária. Além da sinceridade, ocorre a necessidade de também demonstrar respeito pelas opiniões recebidas.

Fazemos questão de trazer esse exemplo do filme, por causa dos aspectos saudáveis, que discutem diretamente o relacionamento entre as pessoas, mas especificamente o que nos interessa é que trata da relação de trabalho na pesquisa, sem a qual não se obtém êxito, pois dependemos somente de boa vontade de quem nos recebe. Claramente assistimos a formulação de dois conceitos: sinceridade e respeito. A incorporação desses conceitos aos nossos trabalhos colabora significativamente com a História Oral, como um exemplo a seguir, por seu conteúdo gerador da aproximação entre as partes.

Pensemos no êxito da pesquisa, cujo pesquisador desdenha, ou demonstra falta de respeito pela opinião alheia. Ou ainda se durante o trabalho não olhar diretamente no rosto das pessoas. Desviar os olhos de seus interlocutores, numa atitude de falta de sinceridade, ou de não interesse pelo dito. Essas são questões a que não atentamos, porém os códigos contidos nos olhares e nas posições do nosso corpo mandam mensagens para nossos interlocutores. E com certeza eles as recebem, decodificam e nos devolvem dentro daquele espaço em que detêm o poder: a palavra, o texto falado, que levamos gravado e depois vamos estudá-lo e trabalhar com ele.

Aqui surgem duas peculiaridades com que Portelli ${ }^{6}$ nos recomenda tomar cuidado quando se trata do trabalho de campo, que são diferença e igualdade, com as quais lidamos, sem nos dar conta, quando da oportunidade em que contatamos os sujeitos, e ativamos nossos instrumentos de pesquisa. Nesses momentos, somos objeto de observações que não percebemos, não identificamos. E são esses olhares lançados sobre nós nessas oportunidades que intermediarão as relações estabelecidas daí pra frente, que findam por intervir no diálogo travado, e que vão atuando como numa espécie de jogo de gato e rato, que podem definir rumos à entrevista. Diferença e igualdade se impõem, naturalmente, a partir

6 PORTELLI, op. cit. Tentando aprender um pouquinho. Algumas reflexões sobre a ética na História Oral. Projeto História, São Paulo, Educ, v. 15, p. 18. 
dos códigos contidos na apresentação de quem solicita a entrevista. Exige que ao chegar na casa da pessoa nos instalemos naturalmente, sem forjar uma igualdade fictícia, falsa. Temos que falar e atuar sinceramente. Para que isso ocorra, exige que manifestemos a contradição polida ${ }^{7}$, falando o que pensamos sem temor, porém sem agressividade, sem alterar a voz, sem zombaria, sem determinadas expressões faciais ou trejeitos corporais.

O momento do contato com a pessoa que se dispõe a prestar uma entrevista é sempre muito delicado. Convém considerar que estamos ocupando o tempo de quem deixa seus afazeres para nos receber. Convém manter certa prudência, diria mesmo uma atenção dobrada, cuidando nas atitudes manifestas. Diante da dificuldade de percebermos a intromissão que cometemos na rotina das pessoas, nosso trabalho pode vir a ser encarado como um fardo demasiado alto para aqueles que nos ajudam em nossas buscas.

Sem que atentemos para os ingredientes apresentados acima, acredito que essa parte da discussão em que entraremos agora não tem necessidade de existir, porque tudo o mais já estaria comprometido, diria mesmo corrompido. O problema já teria começado na concepção do projeto e se estendeu no contato com cada pessoa que procurarmos entrevistar.

Conforme indicado por Verena Alberti, ${ }^{8}$ antes de partir para o contato com as pessoas que iremos entrevistar, é conveniente que nos informemos sobre suas vidas, sobre suas histórias partilhadas com outras pessoas; devemos recorrer às leituras de todo material disponível que nos possa ser útil, para melhor compreender aqueles sujeitos com os quais iremos trabalhar em seguida. Convém definir previamente se realizaremos uma entrevista temática, discutindo determinado assunto, ou entrevista de história de vida, privilegiando o sujeito na história. Depois devemos preparar um roteiro, contendo perguntas abordando os aspectos que buscaremos discutir na entrevista. Atingida essa condição, é hora de entrar em contato com a pessoa escolhida, para realizar o primeiro encontro. Nessa oportunidade, falamos dos nossos propósitos, o porquê de estarmos diante dela, falamos da importância de tomála como integrante no nosso projeto. No momento do primeiro contato, procuramos colher mais informações para perceber se nosso roteiro está dentro da expectativa ou se necessita de algum ajuste. É nessa ocasião que devemos falar da carta de cessão de uso da entrevista, que deve ser assinada pelo entrevistado.

PORTELLI, op. cit., p. 23.

ALBERTI, Verena. Manual de História Oral. 2. ed. Rio de Janeiro: FGV, 2004, p. 81-229. 
Para chegar às tais fontes, compreendidas nos limites convencionais, do que nomeamos indistintamente como História Oral, convém estar atento para não confundir a pessoa que é entrevistada com o que gostaríamos de entender como fonte propriamente dita. Logo, a pessoa que presta um relato não é a fonte. Podemos chamá-la de depoente/entrevistada/relatora. Menos de fonte. Essa pessoa é quem nos ajuda a construir o documento sonoro. É por isso, que devido essa cumplicidade, nesse vai e vem nos encontros para gravar, que alguns de nós chamamos as pessoas, como se nos pertencessem, de minha/meu depoente, minha/meu entrevistada/entrevistado, e assim sucessivamente. A fonte, nesse caso, é a palavra que adquire um caráter documental, por estar convertida em documento sonoro gravado. Conforme entendimento de Danièle Voldman, ${ }^{9}$ que se apóia em Bruno Delmas, ${ }^{10}$ para afirmar que o documento sonoro guarda todas as informações manifestas pela pessoa. Mas Voldman distingue outro segmento, que transcreve os depoimentos para fins de usos das falas, dentro dos objetivos do projeto de cada pesquisador, que quer um material objetivo, factual, contendo dados mensuráveis vertidos para a palavra grafada, para utilizar em seus trabalhos, dentro de determinados contextos.

No primeiro caso, a fonte é a palavra do depoente, que vai aprisionada através de um aparato técnico/tecnológico, convertida em material gravado, que é possível acessar a qualquer hora, porque está disponível para audição, através de um aparelho de audição, uma máquina apropriada. Aqui está contido um entendimento para um dado segmento de historiadores orais, que encaram a fonte dessa forma, onde se processa a idéia de que, através desse mecanismo, a pessoa que concedeu a entrevista pode manter controle sobre o conteúdo do texto sonoro, contra possíveis armadilhas das transcrições. É uma postura da parte do historiador de respeito para com as pessoas que o ajudaram, se envolvendo na construção compartilhada daquele material.

É bem verdade que dado por encerrado o trabalho da gravação, quando o pesquisador parte do estúdio, ou casa do entrevistado, para seu local de origem, e leva consigo o material gravado, a pessoa depoente perde completamente o controle sobre o produto de sua fala. Que ficará sob domínio de outro, que, em certo núme-

9 VOLDMAN, Danièle. Definições e usos. In: FERREIRA, Marieta de M.; AMADO, Janaina. (Orgs.). Usos E abusos da História Oral. 2. ed. Rio de Janeiro: FGV, 1998, p. 3342.

10 DELMAS, Bruno, Les nouvelles archives, problèmes de définition. In: Dictionaire des Archives de France, 1987, p. 178-183, apud VOLDMAN, op cit., p. 33-42. 
ro de casos, mora fora de sua cidade, e até fora de seu estado ou país. Daí a preocupação de manter a fala, por princípio, gravada, sem transcrição.

Preservar a fonte sonora da transcrição implica numa postura política, que compreende, valoriza e respeita o papel que a pessoa depoente desempenha através da palavra dita; é uma atitude que visa preservar na sua forma e no seu conteúdo a expressão da alteridade do indivíduo no coletivo. Essa postura possibilita a percepção de significados que se encontram presentes no silêncio, nas repetições, nas reticências, nas entonações da fala, que remetem a entendimentos através das inflexões das frases, nos prolongamentos das palavras, no prolongamento ou acentuação à sua maneira de certas sílabas na palavra pronunciada, quando a pessoa que fala se resguarda, evitando que determinado conteúdo seja publicizado, ou quando se emociona e sofre por algo rememorado naquelas circunstâncias.

Os depoimentos/relatos/entrevistas das pessoas expressam significados não mensuráveis, à primeira vista, através da altura da voz, quando externa determinado conteúdo, ou quando mudam de assunto e retornam ao anterior, para não abordar algo que não lhes convém. Os recursos da fala nas situações que estamos abordando servem também como instrumentos para acentuar determinados aspectos, que os entrevistados julgam importante transmitir, que supõem ser pouco conhecido ou não-valorizado pelos contemporâneos.

Segundo Verena Alberti, ${ }^{11}$ até aproximadamente 1990 o CPDOC disponibilizava aos pesquisadores, além do material auditivo, o material transcrito correspondente. Mas recentemente optou por disponibilizar apenas algumas entrevistas para audição. Essas entrevistas são acompanhadas de sumário, ficha técnica, e índice temático, contendo os dados que situam o pesquisador em relação à pessoa e às circunstâncias do ato de entrevistar e transcrever o conteúdo gravado.

Um instrumento que muitos pesquisadores adotam, além do material relativo à gravação em si, é o caderno de campo. Nele são anotados todos os dados que envolvem as circunstâncias da entrevista, distinguindo particularmente a pessoa que relata. As atenções do entrevistador são voltadas para perceber e registrar informações relativas às expressões faciais e corporais apresentadas pelas pessoas quando se manifestam. Daí a importância de conduzir o caderno de campo, que reside no fato de se buscar resgatar

11 ALBERTI, op. cit., p. 173. 
aspectos circunscritos às posturas dos sujeitos, quando externam suas respostas em relação a determinados conteúdos que lhes foram requisitados.

Quando o pesquisador retorna para seu espaço de elaboração, se dispondo a escrever seu trabalho, discutindo o material coletado, aquelas informações contidas no caderno de campo, contribuirão demasiadamente facilitando suas interpretações, oportunizando leituras mais profícuas acerca dos conteúdos gravados. Porque ao ouvir uma parte da entrevista, acompanhando através do conteúdo do caderno, para além do expressado, poderá ter a possibilidade de lembrar a atitude da pessoa, nessas circunstâncias terá condições de perceber ingredientes não mensuráveis quando daquele contato, que poderão contribuir para sua análise vir a tornando-se mais rica. É conveniente estar atento com os detalhes que incorporamos na condução da gravação de cada relato, porque cada pessoa é diferente, logo as circunstâncias de análise também devem ser peculiares. Por isso, em História Oral, a análise que fazemos dos materiais nunca é homogênea. Daí estarmos sempre lidando com situações novas, que exigem reflexão apurada, para evitar interpretações precipitadas que comprometam o trabalho realizado.

É isso que trazemos nessa oportunidade para iniciar nossos debates. Obrigado. 